\title{
Review
}

Metabolic Risk/Epidemiology

Diabetes Metab J 2022;46:3-14

https://doi.org/10.4093/dmj.2021.0335

pISSN 2233-6079 · eISSN 2233-6087

DIABET\&S \& METABOLISM JOURNAL

\section{Gestational Diabetes Mellitus: Diagnostic Approaches and Maternal-Offspring Complications}

\author{
Joon Ho Moon, Hak Chul Jang \\ Department of Internal Medicine, Seoul National University Bundang Hospital, Seoul National University College of Medicine, Seongnam, Korea
}

Gestational diabetes mellitus (GDM) is the most common complication during pregnancy and is defined as any degree of glucose intolerance with onset or first recognition during pregnancy. GDM is associated with adverse pregnancy outcomes and long-term offspring and maternal complications. For GDM screening and diagnosis, a two-step approach (1-hour $50 \mathrm{~g}$ glucose challenge test followed by 3-hour $100 \mathrm{~g}$ oral glucose tolerance test) has been widely used. After the Hyperglycemia and Adverse Pregnancy Outcome study implemented a $75 \mathrm{~g}$ oral glucose tolerance test in all pregnant women, a one-step approach was recommended as an option for the diagnosis of GDM after 2010. The one-step approach has more than doubled the incidence of GDM, but its clinical benefit in reducing adverse pregnancy outcomes remains controversial. Long-term complications of mothers with GDM include type 2 diabetes mellitus and cardiovascular disease, and complications of their offspring include childhood obesity and glucose intolerance. The diagnostic criteria of GDM should properly classify women at risk for adverse pregnancy outcomes and longterm complications. The present review summarizes the strengths and weaknesses of the one-step and two-step approaches for the diagnosis of GDM based on recent randomized controlled trials and observational studies. We also describe the long-term maternal and offspring complications of GDM.

Keywords: Diabetes, gestational; Glucose tolerance test; Incidence; Pregnancy outcome

\section{INTRODUCTION}

Pregnancy imposes a metabolic burden on women that accompanies weight gain and insulin resistance. In parallel with the global epidemic of obesity and its related metabolic disorders, gestational diabetes mellitus (GDM) is the most common complication during pregnancy $[1,2]$. GDM has been defined as glucose intolerance of variable severity with onset or first recognition during pregnancy [3]. GDM is associated with adverse pregnancy outcomes, including premature delivery, primary cesarean delivery and preeclampsia $[4,5]$. Prenatal exposure to maternal hyperglycemia leads to hyperinsulinemia in the fetus, which in turn increases the risk of macrosomia, neonatal hypoglycemia, hyperbilirubinemia, etc. Two randomized clinical trials (RCTs) in women with GDM demonstrated the improvement of these pregnancy outcomes in women identified with and treated for GDM compared with women left untreated [6,7]. In addition, offspring born from mothers with GDM were more obese and conveyed more cardiovascular risks to their child continuing to early adulthood [8]. Women who had GDM during pregnancy may develop metabolic perturbations after delivery, which include type 2 diabetes mellitus and cardiovascular disease (CVD) [9-11]. Given the enormous impact of GDM, it is crucial to establish appropriate diagnostic criteria for GDM to prevent complications through proper management.

In clinical practice, the aim of screening and diagnosis of GDM is to identify women at risk for an adverse pregnancy outcome. The first diagnostic criteria for GDM were set in 1964 by O'Sullivan and Mahan [12] using a $100 \mathrm{~g}$, 3-hour oral
Corresponding author: Hak Chul Jang (D) https://orcid.org/0000-0002-4188-6536 Department of Internal Medicine, Seoul National University Bundang Hospital, Seoul National University College of Medicine, 82 Gumi-ro 173beon-gil, Bundang-gu,

Seongnam 13620, Korea

E-mail: janghak@snu.ac.kr
This is an Open Access article distributed under the terms of the Creative Commons Attribution Non-Commercial License (https://creativecommons.org/licenses/by-nc/4.0/) which permits unrestricted non-commercial use, distribution, and reproduction in any medium, provided the original work is properly cited. 
glucose tolerance test (OGTT) to determine diagnostic criteria for GDM according to the maternal diabetes risk. This diagnostic approach for GDM suggested by O'Sullivan et al. has been used to date after Carpenter and Coustan [13] made some modifications to diagnostic cutoff values. In 2010, the International Association of Diabetes and Pregnancy Study Group (IADPSG) presented a new diagnostic approach and diagnostic criteria for GDM based on the results of the Hyperglycemia and Adverse Pregnancy Outcome (HAPO) study [14]. However, the diagnosis of GDM by the IADPSG criteria has more than doubled the incidence of GDM and debate continues over which diagnostic methods are clinically efficient. Another debate regarding GDM is whether GDM affects perinatal and/or long-term adverse outcomes independently of obesity or age because GDM occurs more frequently in obese or older women.

We will address two issues in this article: (1) which diagnostic approach for GDM is more feasible in terms of clinical practice in Korea and (2) long-term outcomes in GDM mothers and their offspring.

\section{ONE-STEP VS. TWO-STEP APPROACH}

\section{Screening and diagnostic approaches for GDM}

Diagnosing GDM in asymptomatic pregnant women involves either a one-step (a diagnostic test performed for all pregnant women) or two-step (screening test followed by a diagnostic test) approach (Table 1). Currently, the Korean Diabetes Asso- ciation recommends both one-step and two-step approaches equally for the diagnosis of GDM.

In 1973, O'Sullivan et al. [15] introduced a $50 \mathrm{~g}$, 1-hour glucose challenge test (GCT) for the screening test, and it was used to determine whether a $100 \mathrm{~g}$, 3-hour OGTT was to be performed to diagnose GDM. In their analysis, they found that the screening threshold of $\geq 130 \mathrm{mg} / \mathrm{dL}$ for the GCT had a sensitivity of $79 \%$ and specificity of $87 \%$ for the detection of women with GDM. The GCT has several advantages, including that it can be performed regardless of the time of last meal or the time of day, and $70 \%$ to $80 \%$ of pregnant women would not require further fasting confirmatory tests (i.e., the $100 \mathrm{~g}$, 3-hour OGTT). A systematic review from the U.S. Preventive Services Task Force in 2013 demonstrated that the GCT is acceptable as a screening test [16]. The sensitivity and specificity of the GCT cutoff of $130 \mathrm{mg} / \mathrm{dL}$ were $99 \%$ and $77 \%$, respectively, when the Carpenter-Coustan cutoffs for the $100 \mathrm{~g}$, 3-hour OGTT were used as the gold standard.

In 1979, the National Diabetes Data Group (NDDG) adopted the GDM diagnostic criteria of O'Sullivan by adding $15 \%$ to each value because venous plasma glucose was measured instead of whole blood glucose [17]. The Carpenter-Coustan criteria, which we currently use as a 'two-step approach', modified the glucose cutoffs for the diagnosis of GDM with the evolution of measurement methods employing enzymatic methods with hexokinase [13]. From the early 1980s to date, the twostep approach has become widely used in the United States and in other countries [18]. In Korea, a two-step approach has be-

Table 1. Diagnosis of gestational diabetes mellitus

\begin{tabular}{|c|c|c|c|c|c|}
\hline & \multirow{2}{*}{ Screening methods } & \multicolumn{4}{|c|}{ Glucose concentration, $\mathrm{mg} / \mathrm{dL}$} \\
\hline & & Fasting & 1-hour & 2-hour & 3-hour \\
\hline \multirow[t]{3}{*}{ One-step } & All women undergo a $75 \mathrm{~g}$ OGTT after fasting for $\geq 8$ hours. & & & & \\
\hline & GDM is diagnosed when $\geq 1$ value exceeds the criteria. & & & & \\
\hline & IADPSG (plasma) ${ }^{a}$ & 92 & 180 & 153 & NA \\
\hline \multirow[t]{6}{*}{ Two-step } & Initial screening: a $50 \mathrm{~g}$ GCT is done without fasting. & & & & \\
\hline & $\begin{array}{l}\text { Women with a positive GCT whose } 1 \text {-hour glucose } \geq 130 \text { to } 140 \mathrm{mg} / \mathrm{dL} \\
\text { undergo a } 100 \mathrm{~g} \text { OGTT after fasting for } \geq 8 \text { hours. }\end{array}$ & & & & \\
\hline & GDM is diagnosed when $\geq 2$ values exceed the criteria. & & & & \\
\hline & O' Sullivan (whole blood) & 90 & 165 & 145 & 125 \\
\hline & NDDG (plasma) & 105 & 190 & 165 & 145 \\
\hline & Carpenter and Coustan (plasma) ${ }^{\mathrm{a}}$ & 95 & 180 & 155 & 140 \\
\hline
\end{tabular}

OGTT, oral glucose tolerance test; GDM, gestational diabetes mellitus; IADPSG, International Association of Diabetes and Pregnancy Study Group; GCT, glucose challenge test; NDDG, National Diabetes Data Group.

${ }^{a}$ Currently recommended criteria from the Korean Diabetes Association for the diagnosis of gestational diabetes mellitus. 
come popular in clinical practice since the mid-1990s [19].

The HAPO study was a multinational, observational study to establish universal GDM diagnostic criteria using a $75 \mathrm{~g}$, 2-hour OGTT [5]. This study demonstrated strong and continuous associations of maternal glucose levels with primary outcomes, such as birthweight, cord blood C-peptide levels, primary cesarean delivery, and neonatal hypoglycemia. In addition, secondary adverse outcomes, including preeclampsia, birth injury, prematurity, and neonatal fat amounts, were similarly associated with maternal glucose levels. However, there were no obvious thresholds for diagnosing GDM. Thus, the IADPSG proposed the OGTT cutoffs, which are average glucose values at an adjusted odds ratio of 1.75 of adverse perinatal outcomes (birthweight $>90$ th percentile, cord C-peptide level $>90$ th percentile, and neonatal percent body fat $>90$ th percentile) [14]. These OGTT cutoffs recommended by the IADPSG are somewhat similar to the Carpenter-Coustan criteria. The IADPSG recommends a one-step approach to diagnose GDM when one or more glucose values exceed the criteria. When the IADPSG criteria were applied in the HAPO study, $64 \%$ of women with GDM were diagnosed with one abnormal value, and only $36 \%$ of women with GDM were diagnosed with two or more abnormal values [20]. These findings explained the doubling of the incidence of GDM with a onestep approach for GDM.

\section{Randomized clinical trials}

Recently, two RCTs comparing the one-step and two-step approaches in terms of perinatal pregnancy outcomes were published (Fig. 1) [21,22]. Hillier et al. [21] investigated whether the one-step or two-step approach for the diagnosis of GDM and its treatment improved perinatal pregnancy outcomes in the setting of standard clinical care. More than 20,000 pregnancies from Kaiser Permanente (Northwest and Hawaii) were included in this study, which consisted of $55 \%$ White individuals and 15\% Asian individuals. With the one-step approach, more diagnoses of GDM were made (one-step vs. two-step, $16.5 \%$ vs. $8.5 \%$ ), but there were no differences in perinatal outcomes, including large for gestational age (LGA) births (8.9\% vs. 9.2\%), perinatal composite outcomes (stillbirth, neonatal death, shoulder dystocia, bone fracture, and any arm/hand nerve palsy) (3.1\% vs. $3.0 \%)$, and primary cesarean section (24.0\% vs. $24.6 \%$ ). A similar proportion that were diagnosed with GDM using the two approaches required medication to manage glucose levels during pregnancy $(42.6 \%$ [ $n=783]$ for

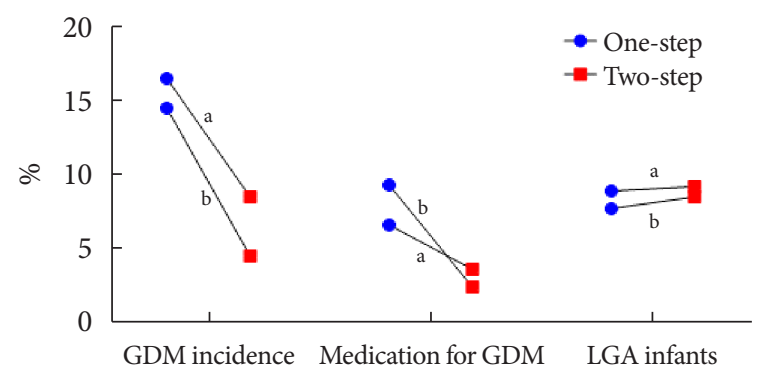

Fig. 1. Summary of two randomized controlled trials comparing the one-step and two-step approaches for the diagnosis of gestational diabetes mellitus (GDM). A one-step approach classifies more women as having GDM and requires more women to be treated for their glucose during pregnancy. The incidence of adverse pregnancy outcomes, including large for gestational age (LGA) births, did not differ between the onestep and two-step approaches. ${ }^{\mathrm{a}}[21],{ }^{\mathrm{b}}[22]$.

one-step and $45.5 \%$ [ $n=431]$ for two-step), meaning that more women who underwent the one-step approach received treatment to manage glucose during pregnancy.

There is some clinical controversy regarding whether a onestep approach leads to overtreatment of GDM versus whether a two-step approach is missing pregnant women who require treatment. The major difference in the diagnostic criteria between the two approaches is one versus two or more abnormal values in the above the criteria. In addition, for a total of $39 \%$ of GDM diagnosed with the one-step approach, the diagnosis was based on the isolated fasting plasma glucose level alone, and half these women had a fasting plasma glucose between 92 and $94 \mathrm{mg} / \mathrm{dL}$. These women who may not have been diagnosed with GDM by the two-step approach, as the cutoff of fasting plasma glucose is more stringent in the one-step approach (one-step vs. two-step, $\geq 92 \mathrm{mg} / \mathrm{dL}$ vs. $\geq 95 \mathrm{mg} / \mathrm{dL}$ ), which ultimately classifies a milder form of hyperglycemia as GDM.

Davis et al. [22] also reported a RCT in 2021 that was a single-center, randomized trial comparing the one- and two-step strategies for GDM screening and treatment. This study enrolled 1,016 pregnant women, and a $50 \mathrm{~g}$ GCT was performed in all participants. If the GCT value was less than $200 \mathrm{mg} / \mathrm{dL}$, participants were randomized to either the IADPSG (75 g OGTT, $n=461$ ) or Carpenter-Coustan group (100 g OGTT, $n=460$ ). GDM was diagnosed based on the results of a $75 \mathrm{~g}$ OGTT in the IADPSG group (regardless of GCT values), and in the Carpenter-Coustan group, GDM was diagnosed based on the results of a $100 \mathrm{~g}$ OGTT when the GCT value exceeded 
Table 2. Strengths and weaknesses of the two screening methods for gestational diabetes mellitus

\begin{tabular}{llc}
\hline & \multicolumn{1}{c}{ One-step } & Two-step \\
\hline Fact & More women are diagnosed GDM (2- to 3-fold compared to the two-step & Less women are diagnosed with GDM. \\
approach). & Easier screening (a 50 g GCT), which does not \\
Strength & Using a 75 g OGTT as in the nonpregnant state & require fasting \\
& GDM screening test can be done at a single visit. & \\
& Based on a large-scale, multinational study assessing adverse pregnancy & \\
& outcomes (HAPO study) & \\
& May prevent long-term maternal and offspring complications by including & \\
& milder forms of GDM (but no differences were found for adverse \\
& pregnancy outcomes from the two RCTs). & \\
All pregnant women need fasting $\geq 8$ hours and undergo a 2-hour OGTT. & $\sim 20 \%$ of women should return for a 3-hour \\
Weakness & More women may suffer from mental stress having been diagnosed and & OGTT with fasting $\geq 8$ hours. \\
& treated for GDM. & \\
& Higher socioeconomic burden &
\end{tabular}

GDM, gestational diabetes mellitus; OGTT, oral glucose tolerance test; HAPO, the Hyperglycemia and Adverse Pregnancy Outcome; RTC, randomized controlled trial; GCT, glucose challenge test.

$130 \mathrm{mg} / \mathrm{dL}$. Their results were consistent with the report by Hillier et al. [21]. The IADPSG group had a significantly higher incidence of GDM than the Carpenter-Coustan group (onestep vs. two-step, $14.4 \%$ vs. $4.5 \%$ ) and a higher number of women with GDM requiring medication (9.3\% vs. $2.4 \%)$. However, there was no significant difference in the primary outcome of LGA neonates ( $7.7 \%$ vs. $8.5 \%$ ), and no differences in other maternal or neonatal adverse pregnancy outcomes, with the exception of a higher risk of neonatal hypoglycemia in the IADPSG group.

Taken together, these RCTs suggest a significant increase in both GDM incidence and health care utilization when using the one-step approach suggested by the IADPSG, with no commensurate improvement in adverse pregnancy outcomes compared to the two-step approach (Table 2).

\section{Observational studies implementing the IADPSG criteria} Kim et al. [23] performed a prospective observational study to investigate the pregnancy outcome in Korean women with GDM diagnosed exclusively by the IADPSG criteria. They found that the incidence of GDM increased nearly three-fold when the IADPSG criteria were applied instead of the Carpenter-Coustan criteria (one-step vs. two-step, $6.2 \%$ vs. $2.1 \%$ ). The women with GDM diagnosed exclusively by the IADPSG criteria but not treated had a higher risk of preeclampsia, LGA neonates and neonatal hypoglycemia than women without GDM. A recent systematic review including eight cohort studies demonstrated that women with GDM diagnosed by the
IADPSG criteria but not by the Carpenter-Coustan criteria or Canadian Diabetes Association criteria had a higher risk for adverse pregnancy outcomes, including preeclampsia, cesarean delivery and LGA birth, than women without GDM [24]. Therefore, milder forms of GDM diagnosed by the IADPSG criteria but not by the Carpenter-Coustan criteria are associated with adverse pregnancy outcomes compared with nonGDM births.

A number of observational studies assessed the adverse pregnancy outcomes of the two screening methods by comparing women who were screened for GDM using the Carpenter-Coustan criteria in the period before the IADPSG criteria were introduced, with women screened with the IADPSG criteria afterward. Duran et al. [25] reported that when the IADPSG criteria were applied in Spanish pregnant women, the GDM incidence increased 3.5 times, but adverse pregnancy outcomes, including gestational hypertension, prematurity, cesarean delivery, LGA birth, and admission to the neonatal intensive care unit, were improved. Another observational study found that application of the IADPSG criteria increased the incidence of GDM and medication, whereas there was no association with pregnancy outcomes, including cesarean delivery, LGA birth and macrosomia [26]. Further studies are needed that compare the long-term maternal and offspring complication rates after implementing the two methods and evaluate the cost-effectiveness of treating more pregnant women who have a relatively milder degree of hyperglycemia. 


\section{OFFSPRING COMPLICATIONS OF GDM}

\section{Fetal hyperinsulinemia and excessive fetal growth}

Hyperglycemia occurring in the middle and late stages of pregnancy increases the concentration of amino acids and fatty acids in the maternal blood and delivers excessive nutrients to the fetus through the placenta [27]. An excessive nutrient supply stimulates fetal pancreatic $\beta$-cells to increase insulin secretion. Fetal hyperinsulinemia induces excessive growth of insulin-sensitive tissues, such as the liver, adipose tissue, and heart. Using ultrasound, fetal abdominal overgrowth can be detected as early as 24 to 28 weeks of gestation [28,29]. This ultimately increases the risk of LGA birth in women with GDM.

A larger fetus born to women with GDM is a major factor contributing to adverse perinatal outcomes. Given that fetal size is positively associated with maternal body mass index (BMI), it is expected that Korean women with GDM who have a relatively lower BMI might have a lower risk of delivering larger babies than Caucasians. A single center study from Korea reported that the incidence of macrosomia decreased in mothers with GDM from 4.5\% before 2010 to $2.8 \%$ after 2010 [30]. However, one interethnic study reported that the incidence of macrosomia in East Asians and Caucasians was not different ( 3 to $4 \%$ in both populations) [31]. Future studies are needed to determine whether the incidence of macrosomia and perinatal complications of Korean mothers with GDM are distinguishable from those of other ethnicities, which may affect the strictness of diagnostic criteria and/or glycemic control during pregnancy in Korean women with GDM.

Given the importance of monitoring fetal size, the American College of Obstetricians and Gynecologists (ACOG) recommends performing ultrasonographic surveillance in mothers with pregnancies complicated by GDM $[32,33]$. The diagnostic threshold and treatment target may need to be individualized by fetal condition (e.g., women with small for gestational age fetuses due to placental insufficiency may require loose glycemic control). No guidelines are currently available for specific indications for glycemic control according to fetal ultrasonographic findings due to the lack of well-designed studies that should be further investigated.

\section{Metabolic perturbations in offspring of mothers with GDM in their childhood and early adulthood}

Neonates born to mothers with GDM have higher body weights at birth than those born to normoglycemic mothers.
The following questions are asked: (1) Would the offspring of mothers with GDM have metabolic perturbations later in their childhood/adulthood? (2) Does tight glycemic control during pregnancy protect offspring from developing metabolic perturbations?

The HAPO follow-up study examined associations of maternal glucose levels of the $75 \mathrm{~g}$ OGTT during pregnancy with childhood adiposity and glucose metabolism. Among 15,812 subjects from 10 centers that participated in the follow-up study, 4,834 children were assessed for their metabolic phenotypes in early childhood. In 10- to 14-year-old offspring, maternal hyperglycemia was linearly and positively correlated with increased total fat percent (measured by air displacement plethysmography), sum of skinfolds, and the incidence of obesity after adjusting for maternal BMI during pregnancy [8]. Consistent with obesity parameters, offspring glucose levels from the $75 \mathrm{~g}$ OGTT and glycosylated hemoglobin were linearly associated with maternal glucose levels during pregnancy independent of maternal and child BMI $[34,35]$. Maternal glucose levels were inversely associated with insulin sensitivity (Matsuda index) and $\beta$-cell function (disposition index and insulinogenic index), which resulted in a higher prevalence of impaired glucose tolerance in offspring from GDM mothers than in offspring from non-GDM mothers (10.6\% of offspring born to mothers with GDM vs. $5.0 \%$ of offspring born to normoglycemic mothers).

In Korean children aged 5 years, BMI was comparable between offspring born to mothers with GDM or to normoglycemic mothers $\left(16.0 \mathrm{~kg} / \mathrm{m}^{2}\right.$ from mothers with GDM vs. $16.1 \mathrm{~kg} / \mathrm{m}^{2}$ from normoglycemic mothers) [36]. Body composition analysis by dual-energy X-ray absorptiometry revealed that total, truncal, and leg fat masses were higher and total lean mass was lower in offspring born to mothers with GDM. Regional fat mass was positively correlated with maternal glucose levels during pregnancy. However, the association between glucose intolerance in childhood and maternal glucose levels was not evident at this age. A subgroup of the HAPO study from Hong Kong showed a significant but modest increase in BMI at age 7 years $\left(15.3 \mathrm{~kg} / \mathrm{m}^{2}\right.$ from mothers with GDM vs. $15.0 \mathrm{~kg} / \mathrm{m}^{2}$ from normoglycemic mothers) [37]. To summarize, BMI differences in East Asian children born to mothers with either GDM or normoglycemia were less evident than those in children of other ethnicities. Therefore, body composition analysis and/or skinfold thickness measurement may be preferable in Asian offspring born to mothers with GDM to assess their adi- 
posity and cardiometabolic risk. Perturbations in glucose tolerance in Asian children born to mothers with GDM should be further investigated.

The molecular basis of offspring adiposity and glucose intolerance is expected to be multifactorial-genetic and epigenetic inheritance, exposure to intrauterine hyperglycemia, rapid adiposity gain after birth, etc. Epigenetic alteration owing to intrauterine hyperglycemia has been assessed by comparing pairwise DNA methylation differences between siblings whose maternal GDM status was discordant [38]. Twelve differentially methylated regions were discovered that included regions in HNF4A and RREB1 that are associated with monogenic diabetes and obesity, respectively. Recent multiomic cord blood analyses from GDM deliveries present possible molecular candidates contributing to the transgenerational cycle of obesity and diabetes [39-41], but further investigation and validation are needed.

\section{MATERNAL COMPLICATIONS OF GDM}

\section{Screening for postpartum type 2 diabetes mellitus}

Women with a previous history of GDM are 10 times more likely to develop postpartum type 2 diabetes mellitus [42-44]. More than $50 \%$ of women with a previous history of GDM develop type 2 diabetes mellitus within 10 years after delivery $[45,46]$. The American Diabetes Association recommends that women with a previous history of GDM be screened for postpartum glucose intolerance by OGTT at 6 to 12 weeks postpartum and to have lifelong evaluations for diabetes at least every 3 years [47]. In a Korean study, the 2-hour glucose from the initial postpartum OGTT was an independent predictor of future development of diabetes, but fasting glucose was not [48]. This emphasizes the need to perform OGTTs in women with GDM after delivery, which should not be restricted to fasting blood tests.

Concurrent measurement of insulin levels during the OGTT to assess $\beta$-cell function may be helpful because women who progressed to type 2 diabetes mellitus in later life had lower $\beta$-cell function (1-hour insulinogenic index and disposition index) during pregnancy $[45,49]$. However, the cutoffs for impaired $\beta$-cell function are lacking and need to be individualized by each institution considering the difficulty of standardizing insulin concentrations.

Multiethnic studies assessing postpartum diabetes reported a higher risk of developing diabetes or impaired glucose toler- ance in Asians than in Caucasians (Ignell et al. [50] 5-fold increased risk of diabetes at 1 to 2 years postpartum; Kousta et al. [51] $44 \%$ vs. $28 \%$ with impaired glucose tolerance at 20 months postpartum). In these studies, Asian women with a previous history of GDM who resided in Western countries had similar BMIs to Caucasians but had a higher risk of postpartum glucose intolerance. The ethnic-specific risk in women who reside in their native regions remains elusive, but Asian women possess a higher risk when exposed to a Western environment or diet.

\section{Risk factors for postpartum type $\mathbf{2}$ diabetes mellitus}

The risk factors for the progression to type 2 diabetes mellitus include maternal age, family history of diabetes, glycemic indices during pregnancy, and genetic predisposition, which are not modifiable after delivery $[10,46]$. Genetic variants, including $\mathrm{CDKN} 2 \mathrm{~A} / 2 \mathrm{~B}, \mathrm{HHEX}$, and CDKAL1, are associated with impaired $\beta$-cell function and an increased risk for postpartum type 2 diabetes mellitus [45,52].

In addition to these nonmodifiable risk factors, clinicians should be aware of improving modifiable risk factors, including lactation, exercise, healthy diet, postpartum weight loss, and improving body composition [46,53-56], all of which correlate with improvement in insulin sensitivity. A Korean study showed that women who lost weight after delivery had improvements in insulin sensitivity and less frequently progressed to type 2 diabetes mellitus, while women who gained weight showed the opposite during 4 years of follow-up [54]. We recently investigated whether higher muscle mass defined by appendicular skeletal muscle mass/BMI was associated with lower insulin resistance and a reduced risk of prediabetes and type 2 diabetes mellitus after delivery in Korean women with a previous history of GDM. We have further discussed the other modifiable risk factors (obesity, diet, exercise, etc.) for progression to postpartum diabetes in another review paper [46].

\section{Cardiovascular disease and metabolic perturbation}

Not surprisingly, GDM is associated with postpartum metabolic perturbation and an increased risk of CVD [57-59]. Recently, the American Heart Association released a scientific statement describing a 2-fold higher risk of developing CVD in women with GDM $[11,60,61]$. This increased risk was independent of the subsequent development of postpartum type 2 diabetes mellitus.

Women who develop GDM already have higher BMIs and 
worse metabolic profiles before pregnancy, which includes higher total cholesterol, triglycerides, and homeostatic model assessment for insulin resistance and lower high-density lipoprotein cholesterol $[62,63]$. Immediately after delivery, women with a previous history of GDM are more obese and have a higher prevalence of metabolic syndrome [64,65]. Over time after delivery, the annual increases in BMI, blood pressure, and total cholesterol did not differ between women with and without GDM. Therefore, women with a previous history of GDM persistently have worse cardiometabolic risk factors than women without GDM over time [64]. As a result, women with a previous history of GDM have increased coronary artery calcium scores and carotid intima media thickness, which are surrogates for atherosclerosis and future CVD, after delivery [66,67]. More surprisingly, women who sustained normoglycemia after a delivery complicated by GDM could not eliminate their future cardiovascular risk, as evidenced by a $>2$-fold prevalence of positive coronary artery calcium scores $(26.3 \%$ vs. 12.9\%) [67].

To date, there are no well-designed prevention trials for CVD in women with a previous history of GDM. It is expected that intensive lifestyle modification (e.g., healthy diet and exercise) would reduce the future development of CVD by improving cardiometabolic risk factors. Postpartum weight loss in Korean women with a previous history of GDM significantly improved blood pressure, lipid profile, \% body fat, insulin sensitivity (Matsuda index) and $\beta$-cell function (disposition index) [54]. Lactation improves maternal cardiometabolic risk, which is further discussed below. Clinicians should also ask for a woman's obstetric history to assess their CVD risk, as a history of preeclampsia, preterm birth, placental abruption, etc. are independent risk factors, along with GDM, for the development of postpartum CVD [60].

\section{Benefits of lactation}

Lactation increases energy consumption (up to $500 \mathrm{kcal} /$ day) due to breastmilk production and reduces the risk of maternal postpartum diabetes in a dose (duration)-dependent manner $[68,69]$. This beneficial effect of lactation in preventing postpartum diabetes lasts up to 30 years after delivery [70,71].

Metabolic outcomes related to pregnancy and/or GDM have been comprehensively examined in the Coronary Artery Risk Development in Young Adults (CARDIA) study, which examined the development and determinants of clinical and subclinical CVD [72]. This study began in 1985 and 1986 with
2,787 women aged 18 to 30 years and follow-up is ongoing for $>30$ years. From the CARDIA study, a longer duration of lactation improved postpartum glucose tolerance and other metabolic perturbations, including metabolic syndrome [73], nonalcoholic fatty liver disease [74], and the amount of visceral and pericardial fat [75]. In other studies, a longer duration of lactation was associated with a lower risk of maternal hypertension [76] and CVD-related hospitalization or mortality [77]. Therefore, lactation has persistent favorable effects on the cardiometabolic health of women. Recent metabolomic analysis has discovered that lactation decreases circulating glycerolipids (triglycerides and diacylglycerol species) and increases phospholipids and sphingolipids, possibly as a result of suppressing endogenous lipogenesis and upregulating catabolism of lipids to produce breastmilk [78].

Strong epidemiologic evidence supports the beneficial effect of lactation on preventing metabolic disorders and CVD. However, its underlying mechanism is less well understood. Prolactin, a hormone secreted from the pituitary during pregnancy and lactation, regulates $\beta$-cell adaptation against increased insulin resistance during pregnancy [79]. In animal studies, $\beta$-cell proliferation occurs during pregnancy via prolactin receptor-STAT5-serotonin-HTR2B activation [80]. During lactation, $\beta$-cell mass expansion and insulin secretion are potentiated with increased circulating prolactin [56]. Human studies support the beneficial role of prolactin in $\beta$-cells, as serum prolactin in pregnancy was positively associated with postpartum $\beta$-cell function. Also, women who progressed to type 2 diabetes mellitus had lower prolactin during pregnancy than those who maintained normoglycemia after delivery [81]. These factors resulted in improved $\beta$-cell function at 4 years postpartum in Korean women with GDM who previously lactated compared to those who did not lactate (40\% increase in disposition index) [56]. Furthermore, higher prolactin levels and prior lactation are linked to improved insulin sensitivity in women of reproductive age and in the general population [8284]. Considering the health benefits of lactation for both infants and mothers, clinicians should strongly promote mothers to lactate as long as possible or consider using breastmilk pumps in working mothers.

\section{CONCLUSIONS}

GDM is associated with adverse pregnancy outcomes and long-term offspring and maternal complications. From a series 


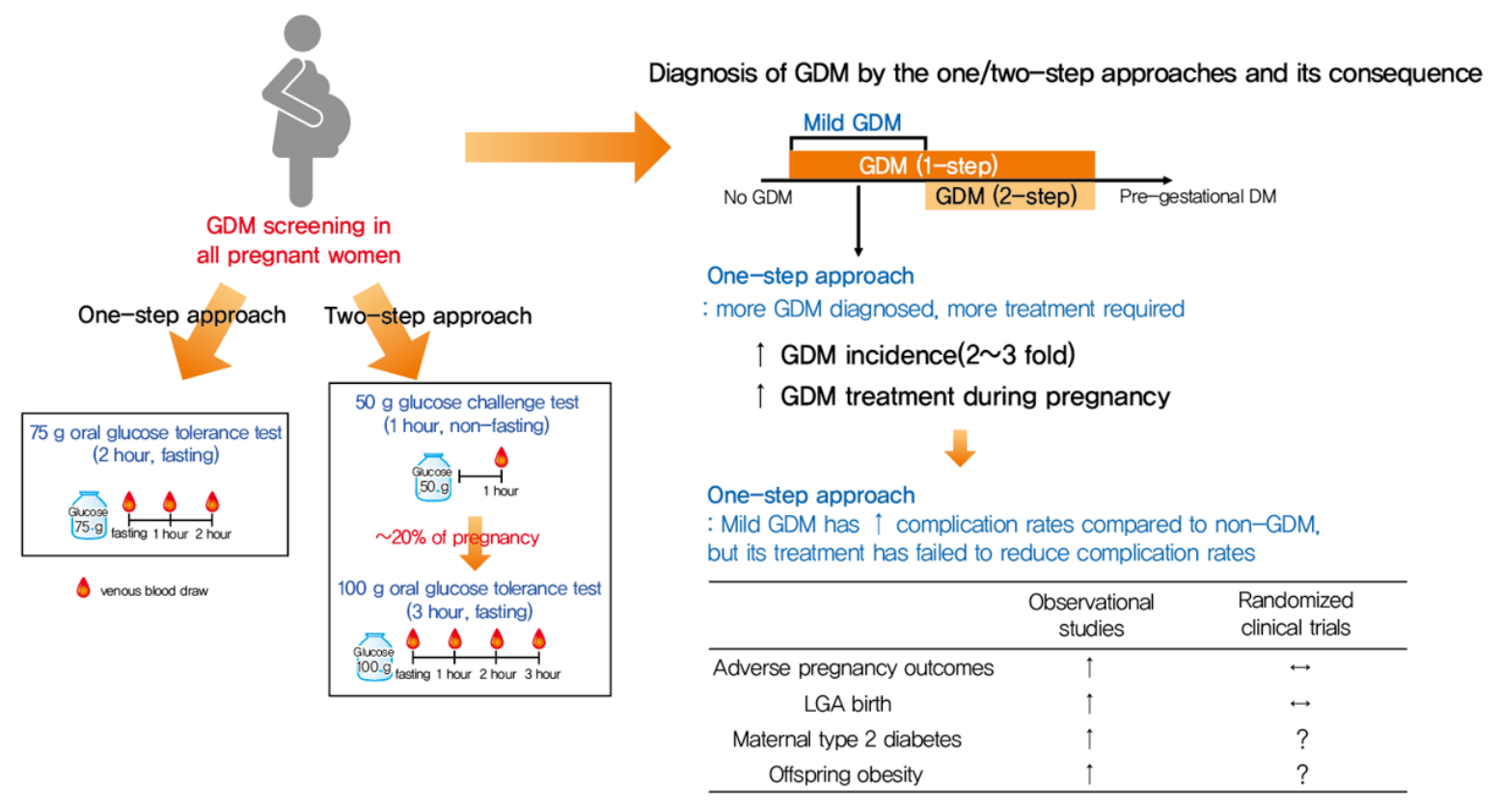

Fig. 2. Schematic summary of the two diagnostic approaches of gestational diabetes mellitus (GDM). DM, diabetes mellitus; LGA, large for gestational age.

of studies, the one-step approach caused two to three times more women to be diagnosed with GDM than the two-step approach. In recent RCTs, adverse pregnancy outcome rates were generally similar between the two methods, although more women were diagnosed with GDM by the one-step approach. Exploratory analyses of the HAPO follow-up study demonstrated a significant increasing trend of worse maternal (glycemic profile) and offspring (adiposity) outcomes from nonGDM to GDM exclusively by the IADPSG criteria to GDM by the Carpenter-Coustan criteria [85]. We have discussed the merits and demerits of the one-step and two-step approaches in this review but controversy remains (Table 2, Fig. 2).

Pros to the one-step approach: There is copious high-level evidence that identification and treatment of milder forms of GDM are of benefit to the individual mother and child [86]. Cons to the one-step approach: There is insufficient evidence to justify the increase in health care costs of broadening the diagnosis by implementing a one-step approach [87].

The Korean Diabetes Association equally recommends the one-step and two-step approaches for the diagnosis of GDM. Taking the controversies into account, choosing the diagnostic approach for GDM should be based upon locally validated evidence, cost-effectiveness, and feasibility in clinical practice. For example, if a lower prevalence of GDM has been estimated or is expected at a certain clinic, ruling out non-GDM pregnancies by a non-fasting $50 \mathrm{~g}$ GCT (two-step approach) may be cost-effective than performing a fasting $75 \mathrm{~g}$ OGTT (one-step approach) in all pregnant women. Currently, only pregnant women are using a 3-hour $100 \mathrm{~g}$ OGTT (two-step approach) for diagnosis. The OGTT conducted by pregnant women will have to be changed to $75 \mathrm{~g}$ OGTT in the future.

Adverse pregnancy outcome rates according to the two diagnostic approaches have been assessed in RCTs, but long-term maternal and offspring complications have not been assessed in RCTs or interventional trials. Future studies are needed to determine whether treating milder forms of GDM can prevent long-term maternal and offspring complications described in this review.

\section{CONFLICTS OF INTEREST}

No potential conflict of interest relevant to this article was reported.

\section{ORCID}

Joon Ho Moon https://orcid.org/0000-0003-1897-0905

Hak Chul Jang https://orcid.org/0000-0002-4188-6536 


\section{FUNDING}

This work was supported by research grants from Seoul National University Bundang Hospital (Grant No. 02-2021-0017 to Hak Chul Jang) and National Research Foundation of Korea (Grant No. 2021R1C1C1009875 to Joon Ho Moon).

\section{ACKNOWLEDGMENTS}

None

\section{REFERENCES}

1. Guariguata L, Linnenkamp U, Beagley J, Whiting DR, Cho NH. Global estimates of the prevalence of hyperglycaemia in pregnancy. Diabetes Res Clin Pract 2014;103:176-85.

2. Kim KS, Hong S, Han K, Park CY. The clinical characteristics of gestational diabetes mellitus in Korea: a National Health Information Database Study. Endocrinol Metab (Seoul) 2021;36: 628-36.

3. Metzger BE. Summary and recommendations of the Third International Workshop-Conference on Gestational Diabetes Mellitus. Diabetes 1991;40 Suppl 2:197-201.

4. Jang HC, Cho NH, Min YK, Han IK, Jung KB, Metzger BE. Increased macrosomia and perinatal morbidity independent of maternal obesity and advanced age in Korean women with GDM. Diabetes Care 1997;20:1582-8.

5. HAPO Study Cooperative Research Group, Metzger BE, Lowe LP, Dyer AR, Trimble ER, Chaovarindr U, et al. Hyperglycemia and adverse pregnancy outcomes. N Engl J Med 2008;358: 1991-2002.

6. Landon MB, Spong CY, Thom E, Carpenter MW, Ramin SM, Casey B, et al. A multicenter, randomized trial of treatment for mild gestational diabetes. N Engl J Med 2009;361:1339-48.

7. Crowther CA, Hiller JE, Moss JR, McPhee AJ, Jeffries WS, Robinson JS, et al. Effect of treatment of gestational diabetes mellitus on pregnancy outcomes. N Engl J Med 2005;352:247786.

8. Lowe WL Jr, Lowe LP, Kuang A, Catalano PM, Nodzenski M, Talbot $\mathrm{O}$, et al. Maternal glucose levels during pregnancy and childhood adiposity in the Hyperglycemia and Adverse Pregnancy Outcome Follow-up Study. Diabetologia 2019;62:598610.

9. Kim C. Management of cardiovascular risk in perimenopausal women with diabetes. Diabetes Metab J 2021;45:492-501.
10. Kim C, Newton KM, Knopp RH. Gestational diabetes and the incidence of type 2 diabetes: a systematic review. Diabetes Care 2002;25:1862-8.

11. Parikh NI, Gonzalez JM, Anderson CA, Judd SE, Rexrode KM, Hlatky MA, et al. Adverse pregnancy outcomes and cardiovascular disease risk: unique opportunities for cardiovascular disease prevention in women: a scientific statement from the American Heart Association. Circulation 2021;143:e902-16.

12. O'Sullivan JB, Mahan CM. Criteria for the oral glucose tolerance test in pregnancy. Diabetes 1964;13:278-85.

13. Carpenter MW, Coustan DR. Criteria for screening tests for gestational diabetes. Am J Obstet Gynecol 1982;144:768-73.

14. International Association of Diabetes and Pregnancy Study Groups Consensus Panel, Metzger BE, Gabbe SG, Persson B, Buchanan TA, Catalano PA, et al. International association of diabetes and pregnancy study groups recommendations on the diagnosis and classification of hyperglycemia in pregnancy. Diabetes Care 2010;33:676-82.

15. O'Sullivan JB, Mahan CM, Charles D, Dandrow RV. Screening criteria for high-risk gestational diabetic patients. Am J Obstet Gynecol 1973;116:895-900.

16. Donovan L, Hartling L, Muise M, Guthrie A, Vandermeer B, Dryden DM. Screening tests for gestational diabetes: a systematic review for the U.S. Preventive Services Task Force. Ann Intern Med 2013;159:115-22.

17. National Diabetes Data Group. Classification and diagnosis of diabetes mellitus and other categories of glucose intolerance. Diabetes 1979;28:1039-57.

18. Gabbe SG. Management of diabetes mellitus in pregnancy. Am J Obstet Gynecol 1985;153:824-8.

19. Jang HC, Cho NH, Jung KB, Oh KS, Dooley SL, Metzger BE. Screening for gestational diabetes mellitus in Korea. Int J Gynaecol Obstet 1995;51:115-22.

20. Sacks DA, Hadden DR, Maresh M, Deerochanawong C, Dyer AR, Metzger BE, et al. Frequency of gestational diabetes mellitus at collaborating centers based on IADPSG consensus panel-recommended criteria: the Hyperglycemia and Adverse Pregnancy Outcome (HAPO) Study. Diabetes Care 2012;35: 526-8.

21. Hillier TA, Pedula KL, Ogasawara KK, Vesco KK, Oshiro CE, Lubarsky SL, et al. A pragmatic, randomized clinical trial of gestational diabetes screening. N Engl J Med 2021;384:895904.

22. Davis EM, Abebe KZ, Simhan HN, Catalano P, Costacou T, Comer D, et al. Perinatal outcomes of two screening strategies 
for gestational diabetes mellitus: a randomized controlled trial. Obstet Gynecol 2021;138:6-15.

23. Kim MH, Kwak SH, Kim SH, Hong JS, Chung HR, Choi SH, et al. Pregnancy outcomes of women additionally diagnosed as gestational diabetes by the International Association of the Diabetes and Pregnancy study groups criteria. Diabetes Metab J 2019;43:766-75.

24. Caissutti C, Khalifeh A, Saccone G, Berghella V. Are women positive for the one step but negative for the two step screening tests for gestational diabetes at higher risk for adverse outcomes? Acta Obstet Gynecol Scand 2018;97:122-34.

25. Duran A, Saenz S, Torrejon MJ, Bordiu E, Del Valle L, Galindo $\mathrm{M}$, et al. Introduction of IADPSG criteria for the screening and diagnosis of gestational diabetes mellitus results in improved pregnancy outcomes at a lower cost in a large cohort of pregnant women: the St. Carlos Gestational Diabetes Study. Diabetes Care 2014;37:2442-50.

26. Pocobelli G, Yu O, Fuller S, Fraser JR, Wartko PD, Chen L, et al. One-step approach to identifying gestational diabetes mellitus: association with perinatal outcomes. Obstet Gynecol 2018; 132:859-67.

27. Freinkel N. Banting lecture 1980. Of pregnancy and progeny. Diabetes 1980;29:1023-35.

28. Kim W, Park SK, Kim YL. Fetal abdominal obesity detected at 24 to 28 weeks of gestation persists until delivery despite management of gestational diabetes mellitus. Diabetes Metab J 2021;45:547-57.

29. Han IK, Min HK, Yim CH, Jeong HY, Chang HC, Han KO, et al. Prediction of large for gestational age infant in women with gestational age infant in women with gestational diabetes mellitus by ultrasound examination. J Korean Diabetes Assoc 1999;23:326-35.

30. Kim M, Park J, Kim SH, Kim YM, Yee C, Choi SJ, et al. The trends and risk factors to predict adverse outcomes in gestational diabetes mellitus: a 10-year experience from 2006 to 2015 in a single tertiary center. Obstet Gynecol Sci 2018;61: 309-18.

31. Silva JK, Kaholokula JK, Ratner R, Mau M. Ethnic differences in perinatal outcome of gestational diabetes mellitus. Diabetes Care 2006;29:2058-63.

32. ACOG Practice Bulletin No. 190: gestational diabetes mellitus. Obstet Gynecol 2018;131:e49-64.

33. Ahmed B, Abushama M, Khraisheh M, Dudenhausen J. Role of ultrasound in the management of diabetes in pregnancy. J Matern Fetal Neonatal Med 2015;28:1856-63.
34. Lowe WL Jr, Scholtens DM, Kuang A, Linder B, Lawrence JM, Lebenthal Y, et al. Hyperglycemia and Adverse Pregnancy Outcome Follow-up Study (HAPO FUS): maternal gestational diabetes mellitus and childhood glucose metabolism. Diabetes Care 2019;42:372-80.

35. Scholtens DM, Kuang A, Lowe LP, Hamilton J, Lawrence JM, Lebenthal Y, et al. Hyperglycemia and Adverse Pregnancy Outcome Follow-up Study (HAPO FUS): maternal glycemia and childhood glucose metabolism. Diabetes Care 2019;42:381-92.

36. Chung HR, Moon JH, Lim JS, Lee YA, Shin CH, Hong JS, et al. Maternal hyperglycemia during pregnancy increases adiposity of offspring. Diabetes Metab J 2021;45:730-8.

37. Tam WH, Ma RC, Ozaki R, Li AM, Chan MH, Yuen LY, et al. In utero exposure to maternal hyperglycemia increases childhood cardiometabolic risk in offspring. Diabetes Care 2017;40: 679-86.

38. Kim E, Kwak SH, Chung HR, Ohn JH, Bae JH, Choi SH, et al. DNA methylation profiles in sibling pairs discordant for intrauterine exposure to maternal gestational diabetes. Epigenetics 2017;12:825-32.

39. Shokry E, Marchioro L, Uhl O, Bermudez MG, Garcia-Santos JA, Segura MT, et al. Impact of maternal BMI and gestational diabetes mellitus on maternal and cord blood metabolome: results from the PREOBE cohort study. Acta Diabetol 2019;56: 421-30.

40. Liu F, Zhao C, Liu L, Ding H, Huo R, Shi Z. Peptidome profiling of umbilical cord plasma associated with gestational diabetes-induced fetal macrosomia. J Proteomics 2016;139:38-44.

41. Cheng X, Chapple SJ, Patel B, Puszyk W, Sugden D, Yin X, et al. Gestational diabetes mellitus impairs Nrf2-mediated adaptive antioxidant defenses and redox signaling in fetal endothelial cells in utero. Diabetes 2013;62:4088-97.

42. Jang HC. Gestational diabetes in Korea: incidence and risk factors of diabetes in women with previous gestational diabetes. Diabetes Metab J 2011;35:1-7.

43. Bellamy L, Casas JP, Hingorani AD, Williams D. Type 2 diabetes mellitus after gestational diabetes: a systematic review and meta-analysis. Lancet 2009;373:1773-9.

44. Vounzoulaki E, Khunti K, Abner SC, Tan BK, Davies MJ, Gillies CL. Progression to type 2 diabetes in women with a known history of gestational diabetes: systematic review and metaanalysis. BMJ 2020;369:m1361.

45. Kwak SH, Choi SH, Jung HS, Cho YM, Lim S, Cho NH, et al. Clinical and genetic risk factors for type 2 diabetes at early or late post partum after gestational diabetes mellitus. J Clin En- 
docrinol Metab 2013;98:E744-52.

46. Moon JH, Kwak SH, Jang HC. Prevention of type 2 diabetes mellitus in women with previous gestational diabetes mellitus. Korean J Intern Med 2017;32:26-41.

47. American Diabetes Association. 2. Classification and diagnosis of diabetes: standards of medical care in diabetes-2021. Diabetes Care 2021;44(Suppl 1):S15-33.

48. Oh TJ, Kim YG, Kang S, Moon JH, Kwak SH, Choi SH, et al. Oral glucose tolerance testing allows better prediction of diabetes in women with a history of gestational diabetes mellitus. Diabetes Metab J 2019;43:342-9.

49. Kwak SH, Choi SH, Kim K, Jung HS, Cho YM, Lim S, et al. Prediction of type 2 diabetes in women with a history of gestational diabetes using a genetic risk score. Diabetologia 2013;56: 2556-63.

50. Ignell C, Shaat N, Ekelund M, Berntorp K. The impact of ethnicity on glucose homeostasis after gestational diabetes mellitus. Acta Diabetol 2013;50:927-34.

51. Kousta E, Efstathiadou Z, Lawrence NJ, Jeffs JA, Godsland IF, Barrett SC, et al. The impact of ethnicity on glucose regulation and the metabolic syndrome following gestational diabetes. Diabetologia 2006;49:36-40.

52. Cho YM, Kim TH, Lim S, Choi SH, Shin HD, Lee HK, et al. Type 2 diabetes-associated genetic variants discovered in the recent genome-wide association studies are related to gestational diabetes mellitus in the Korean population. Diabetologia 2009;52:253-61.

53. Bao W, Tobias DK, Bowers K, Chavarro J, Vaag A, Grunnet LG, et al. Physical activity and sedentary behaviors associated with risk of progression from gestational diabetes mellitus to type 2 diabetes mellitus: a prospective cohort study. JAMA Intern Med 2014;174:1047-55.

54. Moon JH, Kwak SH, Jung HS, Choi SH, Lim S, Cho YM, et al. Weight gain and progression to type 2 diabetes in women with a history of gestational diabetes mellitus. J Clin Endocrinol Metab 2015;100:3548-55.

55. Cho NH, Jang HC, Park HK, Cho YW. Waist circumference is the key risk factor for diabetes in Korean women with history of gestational diabetes. Diabetes Res Clin Pract 2006;71:17783.

56. Moon JH, Kim H, Kim H, Park J, Choi W, Choi W, et al. Lactation improves pancreatic $\beta$ cell mass and function through serotonin production. Sci Transl Med 2020;12:eaay0455.

57. Retnakaran R, Shah BR. Mild glucose intolerance in pregnancy and risk of cardiovascular disease: a population-based cohort study. CMAJ 2009;181:371-6.

58. Tranidou A, Dagklis T, Tsakiridis I, Siargkas A, Apostolopoulou A, Mamopoulos A, et al. Risk of developing metabolic syndrome after gestational diabetes mellitus: a systematic review and meta-analysis. J Endocrinol Invest 2021;44:1139-49.

59. Xu Y, Shen S, Sun L, Yang H, Jin B, Cao X. Metabolic syndrome risk after gestational diabetes: a systematic review and metaanalysis. PLoS One 2014;9:e87863.

60. Grandi SM, Filion KB, Yoon S, Ayele HT, Doyle CM, Hutcheon JA, et al. Cardiovascular disease-related morbidity and mortality in women with a history of pregnancy complications. Circulation 2019;139:1069-79.

61. Kramer CK, Campbell S, Retnakaran R. Gestational diabetes and the risk of cardiovascular disease in women: a systematic review and meta-analysis. Diabetologia 2019;62:905-14.

62. Gunderson EP, Quesenberry CP Jr, Jacobs DR Jr, Feng J, Lewis $\mathrm{CE}$, Sidney S. Longitudinal study of prepregnancy cardiometabolic risk factors and subsequent risk of gestational diabetes mellitus: the CARDIA study. Am J Epidemiol 2010;172:113143.

63. Noussitou P, Monbaron D, Vial Y, Gaillard RC, Ruiz J. Gestational diabetes mellitus and the risk of metabolic syndrome: a population-based study in Lausanne, Switzerland. Diabetes Metab 2005;31(4 Pt 1):361-9.

64. Catov JM, Sun B, Bertolet M, Snyder GG, Lewis CE, Allen NB, et al. Changes in cardiometabolic risk factors before and after gestational diabetes: a prospective life-course analysis in CARDIA women. Obesity (Silver Spring) 2020;28:1397-404.

65. Cho NH, Ahn CH, Moon JH, Kwak SH, Choi SH, Lim S, et al. Metabolic syndrome independently predicts future diabetes in women with a history of gestational diabetes mellitus. Medicine (Baltimore) 2016;95:e4582.

66. Gunderson EP, Chiang V, Pletcher MJ, Jacobs DR, Quesenberry $\mathrm{CP}$, Sidney $\mathrm{S}$, et al. History of gestational diabetes mellitus and future risk of atherosclerosis in mid-life: the Coronary Artery Risk Development in Young Adults study. J Am Heart Assoc 2014;3:e000490.

67. Gunderson EP, Sun B, Catov JM, Carnethon M, Lewis CE, Allen NB, et al. Gestational diabetes history and glucose tolerance after pregnancy associated with coronary artery calcium in women during midlife: the CARDIA Study. Circulation 2021; 143:974-87.

68. Ziegler AG, Wallner M, Kaiser I, Rossbauer M, Harsunen MH, Lachmann L, et al. Long-term protective effect of lactation on the development of type 2 diabetes in women with recent ges- 
tational diabetes mellitus. Diabetes 2012;61:3167-71.

69. Section on Breastfeeding. Breastfeeding and the use of human milk. Pediatrics 2012;129:e827-41.

70. Stuebe AM, Rich-Edwards JW, Willett WC, Manson JE, Michels KB. Duration of lactation and incidence of type 2 diabetes. JAMA 2005;294:2601-10.

71. Gunderson EP, Lewis CE, Lin Y, Sorel M, Gross M, Sidney S, et al. Lactation duration and progression to diabetes in women across the childbearing years: the 30-year CARDIA Study. JAMA Intern Med 2018;178:328-37.

72. Gunderson EP, Lewis CE, Tsai AL, Chiang V, Carnethon M, Quesenberry CP Jr, et al. A 20-year prospective study of childbearing and incidence of diabetes in young women, controlling for glycemia before conception: the Coronary Artery Risk Development in Young Adults (CARDIA) Study. Diabetes 2007; 56:2990-6.

73. Gunderson EP, Jacobs DR Jr, Chiang V, Lewis CE, Feng J, Quesenberry CP Jr, et al. Duration of lactation and incidence of the metabolic syndrome in women of reproductive age according to gestational diabetes mellitus status: a 20 -year prospective study in CARDIA (Coronary Artery Risk Development in Young Adults). Diabetes 2010;59:495-504.

74. Ajmera VH, Terrault NA, VanWagner LB, Sarkar M, Lewis CE, Carr JJ, et al. Longer lactation duration is associated with decreased prevalence of non-alcoholic fatty liver disease in women. J Hepatol 2019;70:126-32.

75. Appiah D, Lewis CE, Jacobs DR, Shikany JM, Quesenberry CP, Gross $\mathrm{M}$, et al. The association of lactation duration with visceral and pericardial fat volumes in parous women: the CARDIA Study. J Clin Endocrinol Metab 2021;106:1821-31.

76. Stuebe AM, Schwarz EB, Grewen K, Rich-Edwards JW, Michels KB, Foster EM, et al. Duration of lactation and incidence of maternal hypertension: a longitudinal cohort study. Am J Epidemiol 2011;174:1147-58.

77. Nguyen B, Gale J, Nassar N, Bauman A, Joshy G, Ding D. Breastfeeding and cardiovascular disease hospitalization and mortality in parous women: evidence from a large Australian
Cohort Study. J Am Heart Assoc 2019;8:e011056.

78. Zhang Z, Lai M, Piro AL, Alexeeff SE, Allalou A, Rost HL, et al. Intensive lactation among women with recent gestational diabetes significantly alters the early postpartum circulating lipid profile: the SWIFT study. BMC Med 2021;19:241.

79. Banerjee RR, Cyphert HA, Walker EM, Chakravarthy H, Peiris $\mathrm{H}, \mathrm{Gu} \mathrm{X}$, et al. Gestational diabetes mellitus from inactivation of prolactin receptor and MafB in islet $\beta$-cells. Diabetes 2016; 65:2331-41.

80. Kim H, Toyofuku Y, Lynn FC, Chak E, Uchida T, Mizukami H, et al. Serotonin regulates pancreatic beta cell mass during pregnancy. Nat Med 2010;16:804-8.

81. Retnakaran R, Ye C, Kramer CK, Connelly PW, Hanley AJ, Sermer M, et al. Maternal serum prolactin and prediction of postpartum $\beta$-cell function and risk of prediabetes/diabetes. Diabetes Care 2016;39:1250-8.

82. Bajaj H, Ye C, Hanley AJ, Connelly PW, Sermer M, Zinman B, et al. Prior lactation reduces future diabetic risk through sustained postweaning effects on insulin sensitivity. Am J Physiol Endocrinol Metab 2017;312:E215-23.

83. Wang T, Lu J, Xu Y, Li M, Sun J, Zhang J, et al. Circulating prolactin associates with diabetes and impaired glucose regulation: a population-based study. Diabetes Care 2013;36:1974-80.

84. Ruiz-Herrera X, de Los Rios EA, Diaz JM, Lerma-Alvarado RM, Martinez de la Escalera L, Lopez-Barrera F, et al. Prolactin promotes adipose tissue fitness and insulin sensitivity in obese males. Endocrinology 2017;158:56-68.

85. Lowe WL Jr, Scholtens DM, Lowe LP, Kuang A, Nodzenski M, Talbot $\mathrm{O}$, et al. Association of gestational diabetes with maternal disorders of glucose metabolism and childhood adiposity. JAMA 2018;320:1005-16.

86. Coustan DR, Dyer AR, Metzger BE. One-step or 2-step testing for gestational diabetes: which is better? Am J Obstet Gynecol 2021;225:634-44.

87. Casey B. Gestational diabetes: on broadening the diagnosis. N Engl J Med 2021;384:965-6. 